\title{
O TEXTO (EN)CENA: LITERATURA E METATEATRALIDADE
}

\author{
NO GIZ-EN-SCÈNE
}

Marco Aurélio Rodrigues ${ }^{1}$

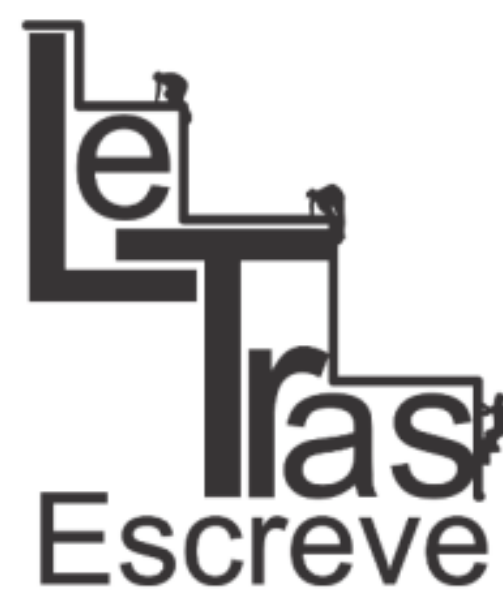

(ISSN 2238-8060)

Resumo: O presente artigo propõe-se a discutir a prática metateatral do Grupo de Leituras Dramatizadas Giz-en-Scène. Formado por alunos e professores da Faculdade de Ciências e Letras, campus da UNESP de Araraquara, a trupe há mais de trinta anos realiza encenações dos textos clássicos com a manutenção do texto em cena. Com um caráter didático, visto que o propósito das montagens é levar ao universo acadêmico o teatro antigo, o grupo, para além de uma discussão sobre as dimensões da apreciação do espectador e interesse desperto pelas apresentações, proporciona um diálogo metateatral, pois ao manter a Literatura em cena, o texto passa a ser parte integrante do processo mimético realizado no espetáculo e, assim sendo, é encenado. A partir da análise da última montagem realizada em Araraquara, com os epigramas de Marcial (séc. I d.C), cuja obra não é dramática, pretende-se demonstrar como a presença do texto em cena reafirma o caráter questionador do teatro e propõe uma reflexão sobre a encenação, o papel do espectador enquanto leitor e, acima de tudo, a performatividade do poeta epigramático.

Palavras-Chave: Teatro; Metateatralidade; Giz-en-Scène; Marcial;

Abstract: This paper proposes to discuss the metatheatrical practice of the Group Giz-en-Scène of Dramatized Readings. Formed by students and professors of the Faculty of Sciences and Letters, campus of UNESP of Araraquara, the troupe realizes more than thirty years ago stagings of the classic texts with the maintenance of the text in scene. With a didactic character, since the purpose of the performances is to bring the ancient theater to the academic universe, the group, apart from a discussion about the dimensions of the spectator's appreciation and interest in the presentations, provides a metatheatrical dialogue, because in keeping the Literature in scene, the text becomes an integral part of the mimetic process realized in the spectacle and, therefore, is staged. From the analysis of the last staging in Araraquara, with the epigrams of Marcial (1st century AD), whose work is not dramatic, it is intended to demonstrate how the presence of the text on the scene reaffirms the questioning character of the theater and proposes a reflection about the perormance, the role of the spectator

\footnotetext{
${ }^{1}$ Bacharel e licenciado em Letras (Língua Portuguesa, Língua Grega Clássica e Língua Latina) pela Faculdade de Ciências e Letras da UNESP de Araraquara, Mestre e Doutor pela mesma Instituição, em Estudos Literários. É, também, Doutor em Estudos Clássicos pela Universidade de Coimbra, Portugal. Atualmente, é Professor e Pós-Doutorando (Capes/PNPD), Departamento de Linguística, subárea de Estudos Clássicos, da Faculdade de Ciências e Letras (UNESP/FCLAr) Araraquara/São Paulo. E-mail: rodriguesaqa@gmail.com
}

https://periodicos.unifap.br/index.php/letras

Macapá, v. 7, n. 3, 2\% semestre, 2017 
as a reader and, above all, the performativity of the epigrammatic poet.

Keywords: Theater; Metatheatricality; Giz-en-Scène; Martial;

\section{INTRODUÇÃO}

Nascido no âmbito da Faculdade de Ciências e Letras, da Universidade Estadual Paulista, campus de Araraquara, interior do Estado de São Paulo, o grupo Giz-en-Scène completou, no ano de 2017, trinta anos de existência. Formado em sua maioria por professores e alunos do curso de Letras, área de Línguas Clássicas (Grego e Latim), o grupo possui reconhecimento em todo o Brasil, colecionando homenagens, traduções, um acervo com mais de mil objetos cênicos e, a-

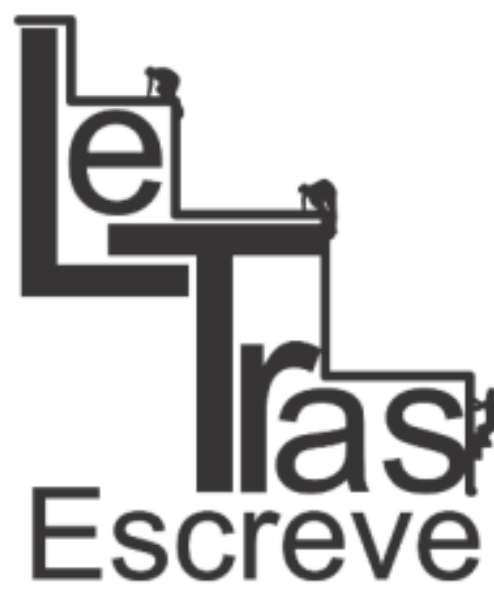

(ISSN 2238-8060) cima de tudo, uma trajetória memorável.

O grupo Giz-en-Scène começou a ser pensado em 1982, com pequenos experimentos cênicos, até que em 1986 preocupações com o nome da companhia apontavam os caminhos de uma sólida formação. O nome Giz-en-Scène deriva da expressão francesa Mise-enScène que Moisés (2003, p. 341) define como o cenário, vestimenta, mobiliário, colocação e movimentação dos atores, etc., de uma peça teatral. Dessa forma, a primeira palavra sugerida foi "giz", pelo professor de sânscrito da Universidade de São Paulo Carlos Alberto Fonseca, como uma expressão da função didática do grupo, um vocábulo que remetia imediatamente a um artefato essencial na vida do profissional da educação. Em seguida, a palavra foi unida à criatividade da professora de grego da FCLAr Maria Celeste Consolin Dezotti, que pensou no interessante trocadilho com a expressão. Por fim, o nome foi definido como Grupo de Leituras Dramatizadas Giz-en-Scène.

A palavra "Leituras", introduzida no nome do grupo, já denunciava uma vertente diferente desta trupe teatral. Com uma proposta inicial de apreciação do texto em cena, aos poucos, foram surgindo 


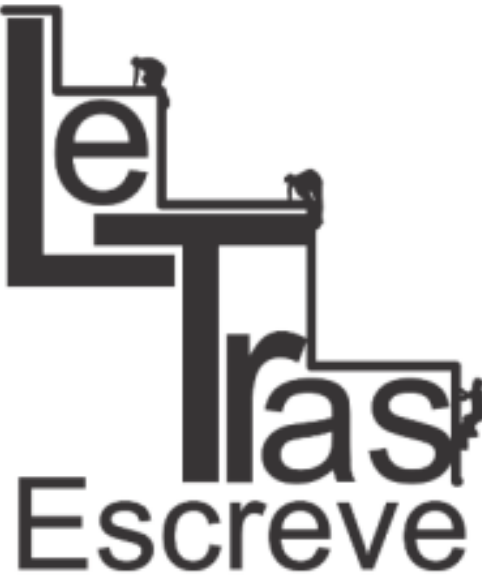

(ISSN 2238-8060)

novas necessidades e invenções estéticas que, unidas a uma postura performática completa, passaram a extravasar a leitura experimental, própria dos atores em fase de reconhecimento da obra dramática. Por conseguinte, certa dificuldade poderia ser encontrada no fato de o texto estar presente em mãos, o que muitas vezes quebraria a ilusão dramática, imobilizaria os atores em cena e poderia desmotivar o espectador. Todavia, não é o que ocorre. Assim como no teatro antigo muitos elementos eram responsáveis por atrair a atenção do espectador, no Giz-en-Scène muitas são as técnicas exploradas para que até mesmo estudantes que não sejam do curso de Letras ou Clássicas se interessem pelo que é apresentado.

Na realidade, este é um dos primeiros grandes aspectos defendidos pelo grupo Giz-en-Scène: a quem se destina sua apresentação. Sempre preocupado com uma função paradidática, o grupo nasceu com a intenção de apresentar o texto clássico para alunos do ambiente acadêmico que desconheciam este tipo de Literatura. Sendo assim, ao longo de trinta anos, estudantes dos mais variados cursos tiveram a oportunidade de conhecer o teatro de Ésquilo, Sófocles, Eurípides, Menandro, Luciano de Samósata, entre outros.

Sendo assim, em tempos em que as discussões acerca da Performance e Recepção do texto clássico ainda começavam a surgir, o Brasil também já possuía no meio acadêmico docentes preocupados com tal questão. É no mesmo período, por exemplo, que Oliver Taplin publica The Stagecraft of Aeschylus: The Dramatic Use of Exits and Entrances in Greek Tragedy (1977), exaustivo trabalho de análise da cena trágica esquiliana, que passa a ganhar respaldo de outros pesquisadores, preocupados também com a frequência com que as representações dramáticas dos clássicos tinham em todo o mundo. A- 
tualmente, grupos como Arc-Net (Europa) e APGRD (Oxford) ${ }^{2}$, compilam informações sobre as representações clássicas, propiciando um aparato crítico e científico aos pesquisadores.

Nesse sentido, Edith Hall (2010, p. 10) afirma que os estudos de Performance e Recepção do teatro antigo, nos dias de hoje, pertencem a uma área denominada Tradição Clássica. Esta área diz muito sobre as preocupações do grupo Giz-en-Scène, visto que se ocupa da tríade explorada no âmbito da Tradição Clássica: tradução, representação e recepção.

\section{O GIZ-EM-SCÉNE}

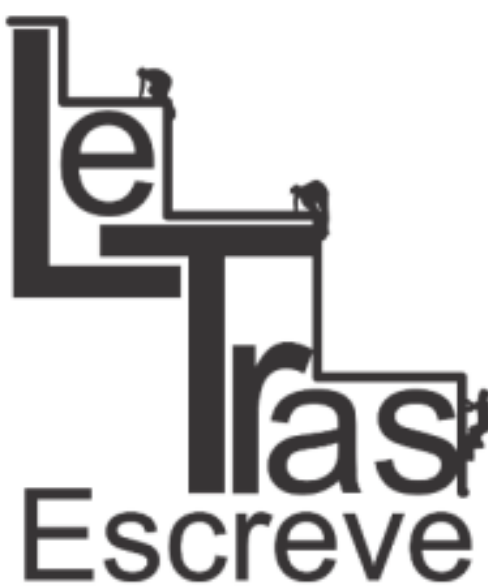

(ISSN 2238-8060)

Trata-se de um longo caminho até a chegada do formato que o grupo Giz-en-Scène alcançou nos dias atuais. Ressaltam Fonseca e Marquetti (no prelo) que um longo caminho é traçado desde a primeira "roupa branca" até os aparatos sofisticados dos quais o grupo faz uso atualmente. A primeira leitura do grupo também sofreu drástica transformação:

[...] Nessa primeira leitura não havia figurino, todos estavam trajados de branco. Os leitores estavam sentados no fundo do palco em cadeiras, das quais

\footnotetext{
${ }^{2}$ O Arc-Net (The European Network of Research and Documentation of Performances of Ancient Greek Drama) é um grupo formado por professores de diversas universidades europeias que, com certa frequência, realizam reuniões para a atualização dos pesquisadores da área de Recepção e Performance do teatro antigo. Tal qual o APGRD (Archives of Performances of Greek and Roman Drama), baseado na Universidade de Oxford, o Arc-Net também é uma base de dados das encenações do teatro antigo em todo o mundo. Em 2014, o autor deste artigo apresentou um trabalho sobre o Giz-en-Scène e o Grupo Thíasos (Universidade de Coimbra) no "2nd Ancient Greek Drama Summer School Challenging Limits: Performances of Ancient Drama, Controversies and Debates", realizado entre os dias 23 de junho a 06 de julho, nas cidades de Láurio, Epidauro e Atenas. No mesmo ano, o Prof. Dr. Fernando Brandão dos Santos, da Faculdade de Ciências e Letras da UNESP de Araraquara, docente da área de Estudos Clássicos, com pesquisa em teatro antigo, esteve presente no evento de Oxford "Spaces \& Places in the Theory and Practice of Greek and Roman Drama", entre os dias 30 de junho e 01 de julho de 2014, explanando sobre o Giz-en-Scène.
} 
se levantavam no momento de sua fala e se dirigiam para o centro da cena. Não havia, portanto, nenhuma marcação de cena de qualquer requinte, nem iluminação especial, nem música, nem cenário. Anote-se que o texto integral da primeira peça lida foi distribuído para toda a plateia, que, para espanto dos leitores, não acompanhou a leitura pelas cópias xerografadas. Essa providência foi abolida nas leituras seguintes.

Dessa forma, mesmo com sua função paradidática, uma das principais preocupações do grupo diz respeito à recepção, pelo público, da encenação e do texto dramático. Em seu repertório, além do teatro grego, latino e sânscrito, o grupo incorporou antologias poéticas antigas e peças modernas em que existisse a influência clássica,

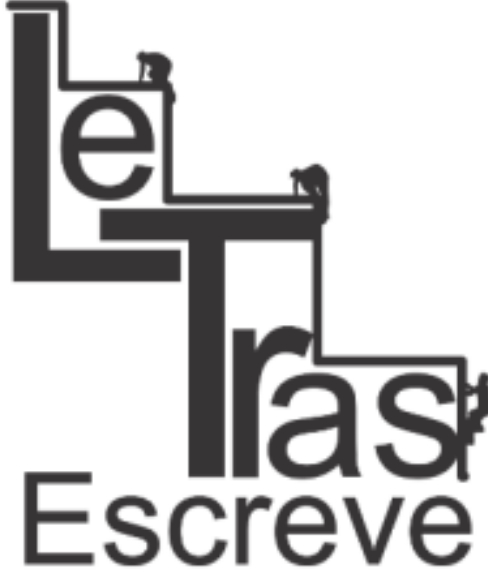

(ISSN 2238-8060) como O Santo e a Porca de Ariano Suassuna. Sendo assim, fazer-se entender pelo espectador é um desafio constante do grupo, como sempre foi, também, a preocupação dos mais sérios autores de teatro, vide o cuidado de Bertolt Brecht, por exemplo, com a recepção do teatro moderno no início do século XX e seu denominado "teatro épico".

Por conseguinte, se a recepção exige atenção constante do grupo, David Wiles (2000, p. 38) ressalta a relevância do papel do ator grego em cena e destaca a importância do corpo, das articulações e de todo o espaço cênico do qual o ator poderia usufruir para explorar melhor a personagem interpretada. No Giz-en-Scène, certa dificuldade poderia ser encontrada no fato de o texto estar presente em mãos, o que muitas vezes imobilizaria os atores em cena e poderia desmotivar o espectador. Todavia, não é o que ocorre. Tal qual o teatro antigo, no Giz-en-Scène muitas são as técnicas exploradas pelo grupo para que, até mesmo estudantes que não sejam do curso de Letras ou Clássicas, se interessem pelo que é apresentado.

Primeiramente, os textos traduzidos pelos professores que 
formam o grupo, ganham uma nova roupagem. Destaca Robbio (2011, p. 6) a importância da tradução do grupo Giz-en-Scène como a de estabelecer uma analogia entre o mundo contemporâneo e o antigo. Por outro lado, encontram-se presentes nas leituras dramatizadas referências ao texto antigo e que dialogam com a modernidade. Marquetti e Fonseca (no prelo), ao citarem inúmeras apresentações do grupo, ressaltam o pendor cômico que surgiu na maioria das apresentações, em boa parte pela presença dos atores, conhecidos do público, mas, em outros casos, justamente por serem explorados aspectos da contemporaneidade em diálogo direto com o drama antigo.

Entretanto, em outros casos, como conclui Mota (2011, p. 3), o debate verbal (esticomitia) entre Hêmon e Creonte, na Antígona de Sófocles, apresentada pelo Giz-en-Scène, atingiu um patamar que o levou a refletir sobre a própria tragédia antiga:

[...] A troca áspera de falas incendiou o teatro, como se estivéssemos assistindo a uma luta de boxe. Parte do público era jovem. E dele vieram demonstrações sonoras de torcida. No mesmo tempo, alguns mais velhos, seja surpreendidos com uma resposta corporal e concreta, seja querendo impor uma certa dimensão polida e sacra aos eventos, estes vigilantes da ordem começaram a pedir silêncio, compostura. Para mim ficou claro naquele momento que a luta entre Hemon e Creonte se duplicara no auditório. Sob os estímulos da esticomitia, a audiência se dividia entre posições antagônicas e co- presentes. O drama de Sófocles se materializava nas perspectivas em conflito, audíveis, presentes.

Assim sendo, o trabalho do grupo transita entre o antigo e moderno, com inserções que atraiam o público leigo, mas sem deixálos conhecer elementos próprios do teatro antigo. Muitos são os registros do grupo presentes em inúmeros trabalhos e mídias. Em um 


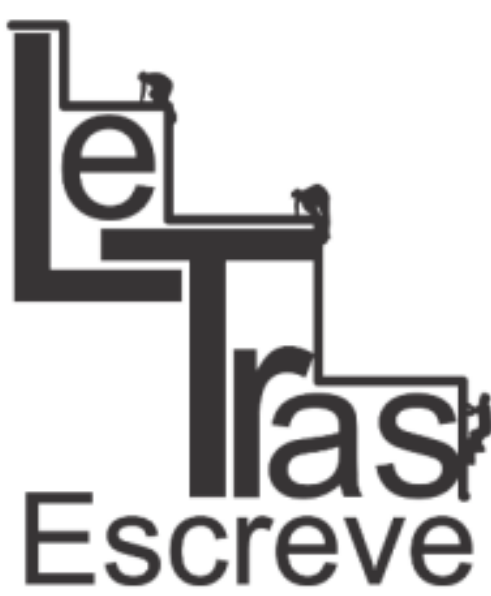

(ISSN 2238-8060)

vídeo disponibilizado no YouTube ${ }^{3}$, há uma cena memorável da comédia Um deus dormiu lá em casa, de Guilherme de Figueiredo, cuja temática é baseada na mitologia grega, e, portanto, passível de adaptação pelo grupo Giz-en-Scène. Quando a entrada de Anfitrião é anunciada pelo arauto, que o compara a Aquiles, o leator (atores/leitores), ao entrar em cena, de forma extremamente performática, além da aparência pouco heroica, faz referência a um gestual muito comum na atualidade, próprio de artistas e personalidades. Tal fato contagiou os espectadores e gerou a manifestação do público.

Um segundo aspecto pontual nas leituras dramatizadas do grupo diz respeito ao cenário e a indumentária dos leatores. McDonald (1992, p. 128) elogia as montagens de Suzuki Tadashi para tragédias gregas justamente pela forma como o diretor constrói a cena e as roupas de suas personagens; quer com a máscara ou sem ela, o diretor ressalta os olhos característicos dos orientais, mantendo a face empalidecida de seus atores e aspectos de sua cultura, como os procedimentos de harakiri e os quimonos.

Já as montagens do grupo Giz-en-Scène, embora tentem explorar com fidelidade, na medida do possível, as vestes gregas, romanas ou indianas, dependendo do contexto, buscam sempre a inovação em diversos aspectos. Certa vez, pela necessidade de executar em cena uma passagem da Medeia, de Eurípides, o grupo resolveu fazer uso de jornais para confeccionar o fundo cênico, criando, dessa forma, um conglomerado de informações e imagens que impossibilitavam ao espectador perceber com nitidez a movimentação necessária e, assim, causavam o efeito desejado.

Tal qual a versatilidade dos atores gregos, os leatores, por maior engajamento que possam ter ao grupo, estão sujeitos ao tem-

\footnotetext{
${ }^{3}$ https://www.youtube.com/watch?v=03XzRSMblqQ Acessado em: 02/06/2017.
} 
po e aos percalços dos outros compromissos do dia-a-dia. Portanto, dificilmente uma apresentação repete os mesmos intérpretes. Ao longo dos anos, muitos foram os alunos e professores que deram vida às personagens lidas pelo Giz-en-Scène e, mesmo com essa rotatividade, os leitores com maior experiência e outras participações transmitem com grande generosidade e auxiliam na estreia dos novos leitores. Esse aspecto garante ao grupo uma solidez dificilmente encontrada e que, amparada na seriedade dos professores que iniciaram o grupo e estão transmitindo o conhecimento, perdurará por muito tempo.

Padel (1992, p. 32) constata que, na Atenas do século V, ocorre

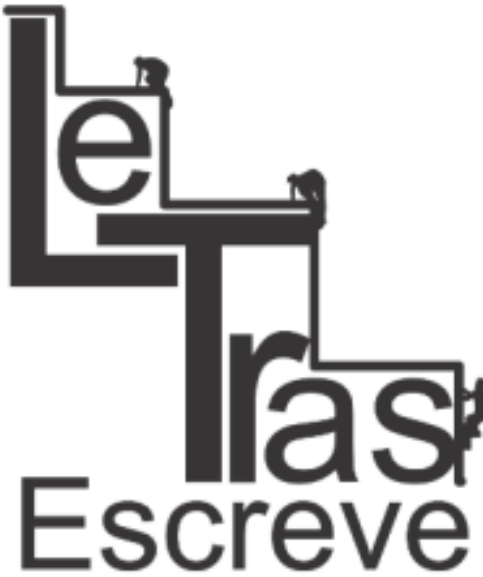

(ISSN 2238-8060) uma situação paradoxal: o homem grego carrega para o espaço aberto do teatro situações pessoais e de foro íntimo. Curiosamente, com o grupo Giz-en-Scène acontece uma situação semelhante: os professores e alunos resgatam do seu íntimo situações de vida, cômicas ou trágicas, depreendem-se do espaço fechado da sala de aula e expõem outro lado, outra faceta, ou ainda, não se esquecendo da principal função a qual se propõe o grupo, outra possibilidade didática.

\section{O METATEATRO}

Ao longo dos anos, o conceito de metateatro, a partir do que foi proposto por Lionel Abel em 1963, foi pouco a pouco sendo modificado e discutido em maior profundidade por diversas áreas dos estudos teatrais. Para o autor (1968, p. 75), partindo das análises de Sófocles e Shakespeare, o conceito de metateatro está relacionado a uma encenação da vida que ocorre de forma teatralizada dentro da própria estrutura teatral e, por isso, transformaria o teatro numa linguagem que nela própria encontra seu questionamento.

https://periodicos.unifap.br/index.php/letras 
A esse respeito, Pavis (2011, p. 240) pondera que, atualmente, a denominação metateatro refere-se a um processo de reflexão do teatro dentro da própria estrutura de encenação teatral. Tal aspecto é reforçado por Schmeling (1982, p. 9), que entende o metateatro o "teatro dentro do teatro", em que o texto produz uma literatura de confrontação, em que o ator e o espectador trocam informações importantes relacionadas à própria obra apresentada em um câmbio que será mantido para além do espaço do teatro.

É desde Alfred Jarry, por exemplo, com seu Ubu Rei (1896), que se encontram os traços de um teatro marcado pela necessidade de uma quebra da ilusão teatral. No entanto, se o objetivo de Jarry era o de confronto com a ilusão proposta pelo teatro burguês ${ }^{4}$, seu efeito vem ao encontro do conceito de metateatralidade, que "é uma propriedade fundamental de toda comunicação teatral" (PAVIS, 2011, p. 241); ou seja, ao propor a quebra da "ilusão teatral", o teatro de Jarry expunha, também, justamente, toda sua teatralidade.

Sendo assim, o metateatro, enquanto uma construção que atrela o real e o não real, e estabelece todo "um jogo de identificação e troca" (PAVIS, 2011, p. 241), é perfeitamente aplicável ao movimen(ISSN 2238-8060) to realizado pelo Grupo de Leituras Dramatizadas Giz-en-Scène, visto que, ao mesmo tempo em que apresenta uma tentativa de representação mimética, quebra a ilusão dramática com a presença do texto e possibilita um diálogo questionador sobre o próprio fazer teatral.

Dentro dessa perspectiva, Pavis (2011, p. 241) apresenta uma importante consideração sobre as produções modernas:

\footnotetext{
${ }^{4}$ Szondi (2001, p. 31) ao teorizar sobre a crise do drama burguês, ressalta que esse tipo de representação dramática entendia o espaço cênico como fechado, encerrado nele mesmo. Em outras palavras, o teatro dramático que chega até a metade do século XVIII leva em consideração unicamente um diálogo entre ator-espectador que impossibilita o questionamento e uma reflexão posterior.
}

https://periodicos.unifap.br/index.php/letras

Macapá, v. 7, n. 3, 2o semestre, 2017 


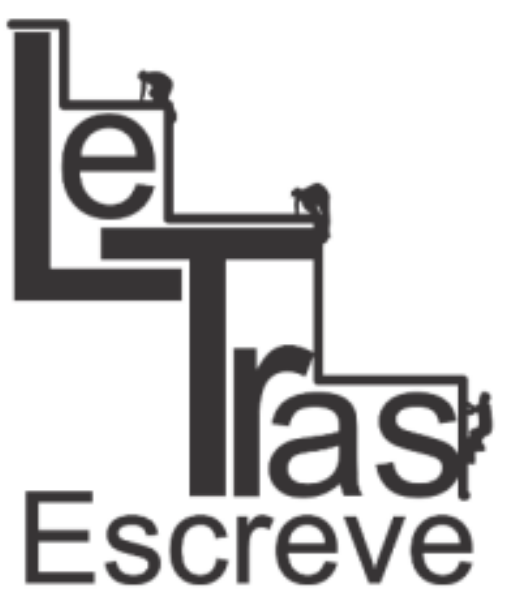

(ISSN 2238-8060)
Uma marcada tendência ou prática cênica contemporânea é não separar o processo de trabalho preparatório (com base no texto, da personagem, da gestualidade) do produto final: assim, a encenação apresentada ao público deve dar conta não só do texto a ser encenado, como da atitude e da modalide dos criadores perante o texto e a atuação. Assim, a encenação não se contenta em contar uma história, ela reflete (sobre) o teatro e propõe sua reflexão sobre o teatro integrando-a, mais ou menos organicamente, à representação. Portanto, não é somente o ator, como no distanciamento brechtiano, que diz sua relação com seu papel, mas o conjunto da equipe teatral que se põe em cena "em segundo grau". Desta maneira, o trabalho teatral passa a ser uma atividade auto-reflexiva e lúdica: ele mistura alegremente o enunciado (o texto a ser dito, o espetáculo a ser feito) à enunciação (a reflexão sobre o dizer). Esta prática comprova uma atitude metacrítica sobre o teatro e enriquece a prática contemporânea $[\ldots]$

Assim sendo, se o metateatro é o discurso reflexivo sobre o próprio fazer teatral, e a metatreatalidade, dentro desse contexto, a característica fundamental desse exercício de encenação, o modo como o Giz-en-Scène se apresenta traz como atributo desta metateatralidade justamente o discurso que potencializa o papel da Literatura dentro do teatro; enquanto representação teatral, a trupe leva à cena o drama antigo e, enquanto metateatro, ela questiona o valor e o papel do texto literário, que se faz presente fisicamente o tempo todo, reforçando sua importância e valor, principalmente dentro dos Estudos Clássicos.

\section{ESTUDO DE CASO: OS EPIGRAMAS DE MARCIAL}

Muito embora uma leitura dos epigramas ${ }^{5}$ de Marcial, autor la-

\footnotetext{
${ }^{5} \mathrm{O}$ gênero epigramático surge na Grécia e se refere a um tipo de inscrição, daí sua curta
} 


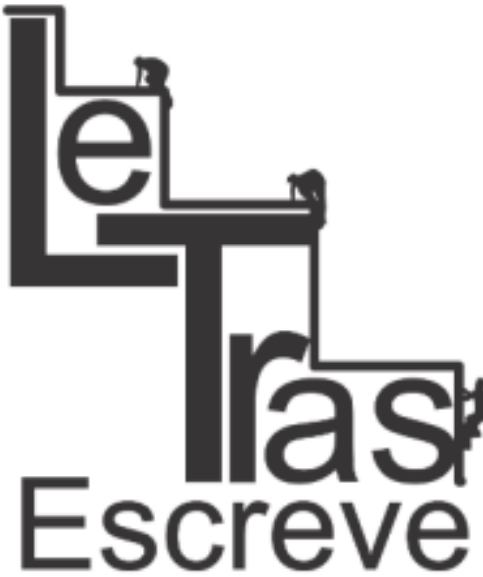

(ISSN 2238-8060) tino do primeiro século D.C., não seja propriamente uma representação teatral, o grupo Giz-en-Scène apresenta a Leitura de forma dramatizada, incorporando elementos cênicos à leitura e, assim transformando uma seleção das pequenas sátiras do autor em mais um exercício de reflexão sobre o lugar dessa exposição na antiguidade.

Apresentada na semana de recepção aos calouros, no dia 08 de março de 2017, a Leitura Dramatizada dos Epigramas de Marcial resultou em um enorme sucesso dentre professores e alunos da Faculdade de Ciências e Letras, da UNESP de Araraquara. Tal o impacto, que muitos estudantes passaram a procurar maiores informações sobre o Giz-en-Scène e sobre as Línguas e Literaturas clássicas ofertadas pela unidade. Esse tipo de situação é um exemplo vivo do exercício de metateatralidade procurado pelo grupo, visto que ela funciona como agente questionador do fazer teatral e, ao colocar o texto em evidência, propõe a reflexão a partir da própria Literatura.

A montagem partia de uma situação de sala de aula, em que um professor, interpretado pelo Prof. Dr. Brunno Vinícius Gonçalves Vieira, docente de Língua e Literatura latina, conduzia a sua classe de alunos, formada pelos Prof. Dr. Fernando Brandão dos Santos (Língua e Literatura grega), Prof. Dr. Marco Aurélio Rodrigues (Língua e Literatura grega), Joana Junqueira Borges (doutoranda em Literatura latina) e Marco Aurélio Abrão Conte (aluno de graduação em Língua e Literatura grega), que recitavam, cada um a sua vez, epigramas que iam dos conteúdos mais banais da Roma antiga até àqueles com forte apelo erótico. O professor, por sua vez, como um regente, dosava a leitura, medindo a entonação e imposição dos alunos, eventualmente intervindo para a recitação de um epigrama em latim. Ao longo da

extensão. Geralmente era versificado e versava sobre o objeto no qual estava inserido. Com o passar do tempo, o epigrama passa a se desvincular dos objetos e passa a ser escrito sobre uma temática diversificada.

https://periodicos.unifap.br/index.php/letras

Macapá, v. 7, n. 3, 2o semestre, 2017

169 


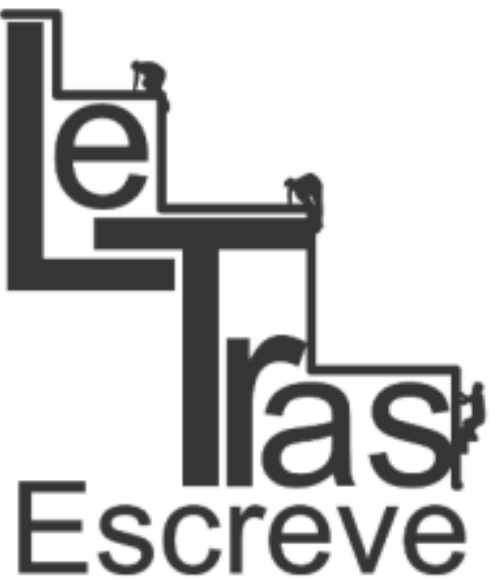

(ISSN 2238-8060) da pelo Prof. Dr. Dejalma Dezotti, aposentado da Faculdade de Ciências e Letras, onde lecionava Língua e Literatura Latinas. Em suas traduções o professor procurou ressaltar a jocosidade presente em Marcial, mas, também, toda a poesia latina, reforçando a presença de uma alta cultura literária no ocidente que remonta há muitos séculos. A esse respeito, segue-se o epigrama VI.36, traduzido por Cairolli (2014, p. 286) e Dezotti (Acervo Giz-en-Scène), respectivamente: 
Pápilo, um pau tão grande tens quanto o nariz, que sempre, ao levantar, podes cheirar.

Teu pau, Papilo, é tão grande e é tão grande o teu nasal, que a cada ereção que tens teu nariz cheira teu pau.

Embora não se esteja realizando uma comparação tradutória, em caráter ilustrativo, fica evidente no epigrama apresentado a forma condensada, característica deste gênero, que, na versão do Gizen-Scène, embora se estenda, propicia um jogo rítmico pertinente à dramatização realizada. Não se trata pura e simplesmente da reprodução de um epigrama de cunho erótico e jocoso, mas a transmissão ao espectador de toda uma brincadeira de leitura avaliada por um "professor" e recitada por "alunos", que, enquanto reproduziam tais poemas, gesticulavam, riam e, assim, criavam uma identificação do espectador com o ambiente escolar.

Dessa forma, a encenação do grupo Giz-en-Scène colocou em cena um ambiente conhecido do espectador e levou aos alunos de diversos cursos um material ao qual eles não teriam fácil acesso, apresentando, também, uma faceta do mundo antigo que difere muito do universo imponente das obras clássicas "populares" presentes na tradição.

\section{CONCLUSÃO}

Ao colocar os alunos com pergaminhos nas mãos, diante de um professor-regente, recitando epigramas, o grupo de Leituras Dramatizadas Giz-en-Scène não apenas encenou um aspecto do cotidiano, mas suscitou no espectador a reflexão sobre esta leitura, sobre a propagação do gênero epigramático na antiguidade clássica e, mais 
do que isso, deixou que o espectador enxergasse nas palavras daqueles atores o próprio texto materializado, fruto do estudo, da dedicação, da experiência da vida acadêmica.

Como se procurou demonstrar no presente artigo, o conceito de metateatro, o "teatro dentro do teatro", e esse discurso proporcionado pela metateatralidade, ou seja, pela discussão da qualidade de potência da própria Literatura dentro da dramatização teatral, é a base que rege as representações do Grupo de Leituras Dramatizadas Giz-en-Scène, não só por seu caráter didático, que já opera como um agente distanciador da ilusão teatral, mas, também, pelo exercício perscrutador que propõe ao espectador.

Portanto, reproduzindo uma cena social familiar aos especta-

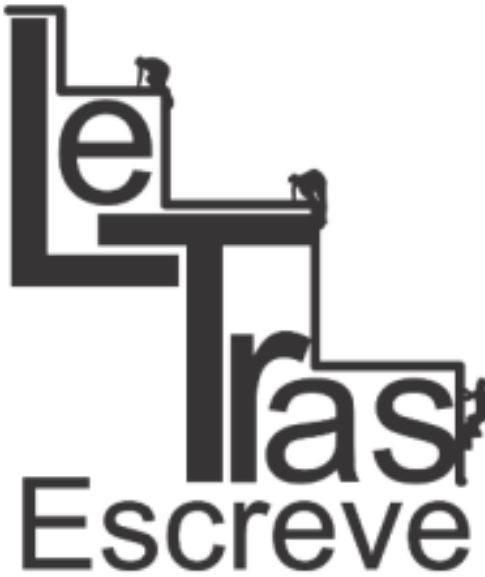

(ISSN 2238-8060) dores, aquela da sala de aula, mantendo a presença física do texto em cena, não aquele próprio do universo teatral, mas inserindo um gênero literário dentro de outro, com elementos de teatralidade e, por fim, discutindo a própria representação de tais versos, a proposta performática do grupo atualiza a percepção sobre o mundo antigo, discute a criação teatral pelo próprio teatro e desperta na audiência uma nova vivência social. Se por um lado, os elementos de metateatralidade presentes nas apresentações do grupo Giz-en-Scène possam refletir uma discussão sobre o próprio fazer teatral, por outro, na montagem apresentada, reafirmam a condição do texto literário, sua difusão oral e performática em Roma, sua importância e despertam a curiosidade do espectador contemporâneo. Assim, a encenação revisita grandes teorias do teatro, discute nomes como os de Aristóteles, Marcial, Becket e Brecht e confronta o homem em sua própria formação como agente apreciador e transformador da sociedade. 


\section{REFERÊNCIAS}

$A B E L, L$. Metateatro. Uma visão nova da forma dramática. Tradução de Bárbara Heliodora. Rio de Janeiro: Zahar Editores, 1968.

CAIROLLI, F. P. Marcial brasileiro. 2014. 498 p.; Tese (Doutorado em Letras Clássicas e Vernáculas) - Faculdade de Filosofia, Letras e Ciências Humanas da Universidade de São Paulo, São Paulo, 2014.

FONSECA, C. A. da; MARQUETTI, F. R. Giz-en-Scène: rolliuide que se cuide. (no prelo)

HALL, E.; HARROP, S. (orgs.) Theorising Performance. Greek Drama, Cultural History and Critical Practice. Great Britain: Duckworth, 2010.

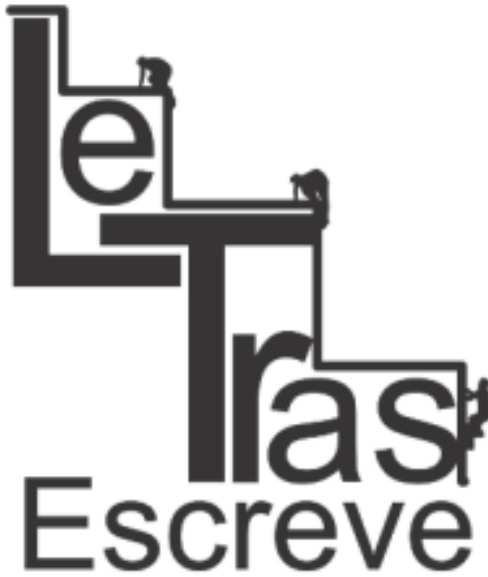

(ISSN 2238-8060) MCDONALD, M. Ancient sun, modern light. Greek drama on the modern stage. New York: Columbia University Press, 1992.

MOISÉS, M. Dicionário de termos literários. 12.ed. São Paulo: Cultrix, 2004.

MOTA, Marcus. Tragédia grega em cena: o grupo Giz-en-scène. (no prelo)

PADEL, R. In and out of the mind: greek images of the tragic self. Princeton: Princeton University Press, 1992.

PAVIS, P. Dicionário de Teatro. Tradução sob a direção de J. Guinsburg e Maria Lúcia Pereira. 3.ed. São Paulo: Perspectiva, 2011.

ROBBIO, Matías Sebastián Fernandez. Del diálogo al texto dramatico: una adaptación brasileña de Los Diálogos de Los Muertos de Luciano de Samosata. (no prelo)

SCHMELING, M. Métathéâtre et intertexte. Aspects du théâtre dans le théâtre. Paris: Lettres Modernes, 1982.

SZONDI, P. Teoria do drama moderno (1850-1950). Tradução: Luiz Sérgio Repa. São Paulo: Cosac \& Naify, 2001.

TAPLIN, O. The Stagecraft of Aeschylus: The Dramatic Use of. Exits 
and Entrances in Greek Tragedy. Oxford: Clarendon Press, 1977.

WILES, D. Greek theatre performance: an introduction. Reino Unido:

Cambridge University Press, 2000.

Artigo recebido em: 07/06/2017

Aceito em: 29/11/2017

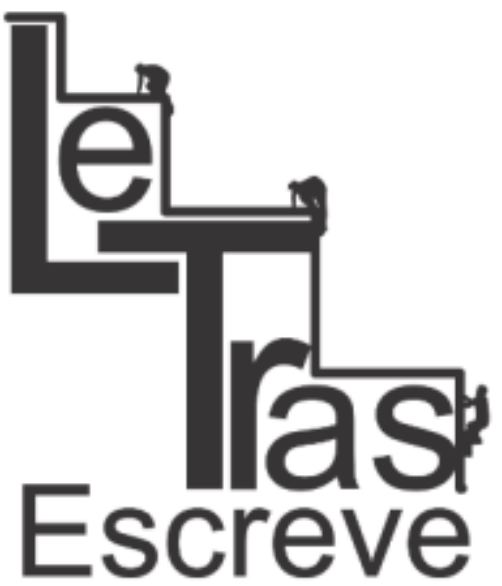

(ISSN 2238-8060) 